\title{
Endoscopic retrograde cholangiopancreatography in the elderly: a review of most recent personal experience
}

\author{
Giovanni D De Palma*, Bruno Amato, Saverio Siciliano, Francesco Maione, Dario Esposito, Nicola Gennarelli, \\ Marcello Persico, Stefania Masone, Giuseppe lannone, Pietro Forestieri
}

From 26th National Congress of the Italian Society of Geriatric Surgery

Naples, Italy. 19-22 June 2013

\section{Introduction}

It is well documented that the incidence of biliary tract pathologies increases with age, and as life expectancy is rising, it is expected that the prevalence of advanced age patients with bile duct pathologies will correspondingly increase leading to an increase in the demand for endoscopic retrograde cholangiopancreatography (ERCP) interventions.

Our aims are to assess the outcomes, safety and complications associated with ERCP performed in an elderly population.

\section{Methods}

Patients aged 80 years or over referred for ERCP from January 2008 to December 2012, were identified and retrospectively reviewed.

\section{Results}

Eighty-three patients (58 females, mean age $84.6 \pm 3.9$ years old) underwent 94 procedures (1-3 procedures/ patient). The main indications were cholangitis (53.7\%), choledocholithiasis (19.4\%) and blocked stents (14.6 percent). Malignancies represented $12.3 \%$ of indications. The overall success rate was $92.5 \%$. Minor events occurred in 19 patients $(22.9 \%)$ percent (tachycardia 5 , desaturation 11, transient hypotension 3). Major events occurred in 4 patients (4.8\%): delayed post sphincterotomy bleeding (five days post-procedure) in 1 patient, cholangitis in 2, and one mild pancreatitis. Four deaths occurred within one month of ERCP, due to advanced malignancies.

\section{Conclusion}

Our study showed that ERCP is safe in the elderly population. Minor complications are usually transient and related to sedation, and mortality is usually related to severity of illness and underlying malignancies.

Published: 16 September 2013

\section{References}

1. Siegel HJ, Kasmin FE: Biliary tract diseases in the elderly: management and outcomes. Gut 1997, 41:433-5.

2. De Palma GD, Catanzano C: Stenting or surgery for treatment of irretrievable common bile duct calculi in elderly patients? Am J Surg 1999, 178(5):390-3.

3. Sugiyama M, Atomi Y: Endoscopic sphincterotomy for bile duct stones in patients 90 years of age and older. Gastrointest Endosc 2000, 52:187-91.

4. Cardin F, Andreotti A, Manuel Zorzi M, Terranova C, Martella B, Amatoa B, Militello $C$ : Usefulness of a fast track list for anxious patients in a upper Gl endoscopy. BMC Surgery 2012, 12(Suppl 1):S11, doi:10.1186/1471-248212-S1-S11.

5. De Palma GD, Galloro G, Siciliano S, Catanzano C: Endoscopic stenting for definitive treatment of irretrievable common bile duct calculi. A longterm follow-up study of 49 patients. Hepatogastroenterology 2001, 48(37):56-8.

doi:10.1186/1471-2482-13-S1-A13

Cite this article as: De Palma et al:: Endoscopic retrograde cholangiopancreatography in the elderly: a review of most recent personal experience. BMC Surgery 2013 13(Suppl 1):A13.

\footnotetext{
* Correspondence: giovanni.depalma@unina.it

Department of Gastroenterology, Endocrinology and Surgery. Center of

Excellence for Technical Innovation in Surgery, University of Naples Federico II, School of Medicine, Italy
} 